\title{
Future Foreign Language Teachers' Readiness for Innovative Activity in the Context of Smart Education: The Results of the Pedagogical Experiment
}

\author{
Tetiana Vakaliuk $^{1, *}$, Olha Osova ${ }^{2}$, Dmytro Antoniuk ${ }^{1}$, Inesa Novitska ${ }^{3}$ \\ ${ }^{1}$ Department of Software Engineering, Zhytomyr Polytechnic State University, Zhytomyr, 10005, Ukraine \\ ${ }^{2}$ Department of Foreign Philology, Municipal Establishment “Kharkiv Humanitarian-Pedagogical Academy” of Kharkiv Regional \\ Council, Kharkiv, 61000, Ukraine \\ ${ }^{3}$ Department of Pedagogy, Vocational Education and Management of Educational Institutions, Zhytomyr Ivan Franko State University, \\ Zhytomyr, 10008, Ukraine
}

Received October 20, 2020; Revised December 3, 2020; Accepted December 20, 2020

\section{Cite This Paper in the following Citation Styles}

(a): [1] Tetiana Vakaliuk, Olha Osova, Dmytro Antoniuk, Inesa Novitska , "Future Foreign Language Teachers' Readiness for Innovative Activity in the Context of Smart Education: The Results of the Pedagogical Experiment," Universal Journal of Educational Research, Vol. 8, No. 12B, pp. 8223-8232, 2020. DOI: 10.13189/ujer.2020.082626.

(b): Tetiana Vakaliuk, Olha Osova, Dmytro Antoniuk, Inesa Novitska (2020). Future Foreign Language Teachers' Readiness for Innovative Activity in the Context of Smart Education: The Results of the Pedagogical Experiment. Universal Journal of Educational Research, 8(12B), 8223-8232. DOI: 10.13189/ujer.2020.082626.

Copyright $\odot 2020$ by authors, all rights reserved. Authors agree that this article remains permanently open access under the terms of the Creative Commons Attribution License 4.0 International License

\begin{abstract}
The article analyzes the approaches to defining the essence of the concepts "readiness" and "future foreign language teachers' readiness for innovative activity in the context of smart education". The analysis of scientific sources made it possible to find out the specifics of the content nature of the concept under study and to provide our vision of the problem. The readiness of a foreign language teacher for innovative activity is defined as the ability to organize, realize, and regulate vocational and pedagogical activities. It is determined by many factors, among which the most important is the formation of educational, linguistic, and innovative competences. Its structure, which is represented by the motivational, cognitive, creative, reflexive, valeological, technological, and personal components, has been specified. They are based on the provisions on the criteria of teachers' readiness for innovative professional activity and the researchers' models of teacher training for innovation. Integrating the results of domestic and foreign scientists' researches on the specificity of the level-based approach to determining the levels of students innovative competence, and taking into account the experience of our work at a higher educational institution, allowed specifying three levels of formation of future foreign language teachers' readiness for innovative activity in the context of smart
\end{abstract}

education and their characteristics. The theoretical methods used during the experimental study included analysis, synthesis, generalization, modeling, comparison, induction, deduction. The statistical analysis of the data was carried out using the non-parametric Pearson xi-square test.

Keywords Future Foreign Language Teachers', Readiness, Innovative Activity, Smart Education, Pedagogical Experiment

\section{Introduction}

The modern information society has transformed knowledge, information, and technology into the main resource. Scientific developments have become the main driving force of the economy of developed countries. The level of education, professionalism, the ability to learn in the conditions of smart education, and creative thinking have become the most valuable qualities of employees.

Nowadays, the state of the socio-economic development of Ukraine requires training of educated, moral, mobile, constructive and practical people capable 
of cooperation, intercultural collaboration, who have a deep sense of responsibility for the fate of the country, as well as its establishment as a sovereign, independent, democratic, social, state of law. The leading role in this process belongs to foreign language teachers.

One of the important qualities of a modern foreign language teacher, which conditions their success and professional competitiveness, is their readiness to innovate in professional activities.

Today we have a clearly defined legislative base for higher education: the Laws of Ukraine "On Education", "On Higher Education" and the National Strategy for the Development of Education in Ukraine for 2012-2021, which reflect the trends in the content, forms, and methods for pedagogical staff training. They are based on progressive concepts and the introduction of technological innovations.

Theoretical principles of information and communication technologies application in professional training of future teachers and conditions preparing for using information and communication technologies in future professional activity are presented in researches by O.I Teplytskyi, S.O. Semerikov, V.M Soloviov [1], K.V Hodlevska, Yu.M. Kobiuk [2]. Theoretical and methodological principles of preparing future teachers for innovative professional activity were investigated by L.V. Kozak [3] and I.V Havrysh [4], L.O. Petrychenko [5].

The group of authors considers the possibilities of using blended learning technology in the process of teaching foreign languages in high school. They argue that the model is optimal for those students who for various reasons are forced to study at home. It will be especially effective for students with special needs, programs of work with which are just beginning to be developed in Ukraine. It is very important to maintain the total number of hours devoted to learning foreign languages in schools, but this task is complicated by the conditions of learning at home. The model allows to successfully solve this problem because it provides students with continuous access to educational materials, the opportunity to choose a convenient time for learning, and receive teacher advice online [20].

O.O. Mosiiuk [6] developed the models of training future teachers of mathematics for innovative research activity. L.I. Morska [7] and O.A. Honcharova [8] made a significant contribution to the development of the problem concerning the formation of foreign language teachers' readiness for innovation.

It should be noted that one of the least investigated aspects in this area is the approach to the development of tools aimed at determining the results of the formation of future foreign language teachers' readiness for innovative activity in the context of smart education. Thus, there is a contradiction between the necessity to diagnose the level of formation of future foreign language teachers' readiness for innovative activity in the context of smart education and the lack of diagnostic and criterion instruments for its study.

Therefore, the relevance of the problem and insufficient level of its theoretical and practical development allowed us to determine the purpose of our study - to define the essence of the concept "future foreign language teachers' readiness for innovative activity in the context of smart education", and to specify the criteria and indicators of its formation in future foreign language teachers.

The pedagogical experiment was conducted based on the Municipal Establishment "Kharkiv Humanitarian Pedagogical Academy" of Kharkiv Regional Council and the Khmelnytskiy Humanitarian-Pedagogical Academy during 2010-2018. The control group consisted of 109 students of the Faculty of Foreign Philology. The experimental group also included 110 students - future foreign language teachers.

To solve the aim and tasks of the study, the following methods have been used:

- theoretical - retrospective analysis; abstraction, concretization and generalization of theoretical positions to analyze scientific research thesaurus; synthesis, sources systematization to form the scientific apparatus and to formulate the basic concepts; comparative analysis, structuring and generalization to study the structure of future foreign language teachers' readiness for innovative activity in the context of smart education; a comprehensive analysis of the content, forms and methods of innovative pedagogical practice to develop theoretical and methodical principles for the implementation of innovative technologies in foreign language teaching; empirical - pedagogical observation, questionnaires, testing, interviews, self-evaluation; study of the educators' experience in the innovative activity, analysis of our own pedagogical experience to define the proposed theoretical and methodological principles of forming future foreign language teachers' readiness for innovative activity in the context of smart education;

- mathematical statistics methods: the method of statistical data processing based on Pearson's criterion for quantitative and qualitative analysis of the experimental work

\section{Theoretical Background}

Modern realities and requirements of the society define the leading task of professional and pedagogical training of future foreign language teachers. It is the formation and development of a creative teacher personality capable of innovative activities. Therefore, the growing importance is attached to the modern teacher's willingness to innovate in the context of smart education, which is one of the key educational trends. In English, the lexical unit "smart" has 
many different versions of translation, which are based on such meanings as intelligent, technological, and effective. Initially, this term was used in the context of aerospace technologies, which were marked by the transition to new materials and the use of their innovative capabilities, as well as achievements in the field of electronics and information technology [9]. Gradually, it has spread to other branches of science. In the educational context, the vast majority of teachers identify the concept with the use of technological innovations and interactive teaching methods that contribute to the formation of future specialists' professional competencies based on "systemic multidimensional vision and study of disciplines, taking into account their multifaceted and continuous content updating" [10].

Intensive introduction of modern technologies, services, and Internet resources has led to a new stage in the development of information space. Today it is referred to as the "smart society". It became especially popular after the Seoul G20 summit (2010) when strategic directions for the development of smart technologies or "smart" technologies were announced in the world-leading countries (Germany, South Korea, the Netherlands, etc.) [11]). A smart society is characterized by rapid changes in the external environment, adaptation to new conditions, independent development. Accordingly, the tasks of higher education have changed. Now they include training professionals with creative potential, able to live in the modern information society, able to work in new ways, changing the nature of the interaction. Given these characteristics of the modern society, there is a need to develop new relevant areas of education - the emergence of "flexible learning in an interactive educational environment" [12, p. 54], which is carried out with content from all over the world - "smart learning" [12, p. 54]. The purpose of smart learning is to form future professionals' skills required for carrying out effective professional activities in the conditions of the digital society and rapid economic development. Smart learning involves using electronic content and comprehensive modernization of learning technologies. It calls for the realization of the didactic potential of innovative learning technologies, multimedia tools, and leads to qualitative changes in the subject interaction.

The concept of modern education is the formation of an intelligent learning environment, ensuring the continuous development of its participants' competencies using technological innovation. The concept of smart education involves learning mobility, flexible use of didactic material, and a variety of multimedia means, an independent search of information and its acquisition, the introduction of technological innovations in pedagogical practice, generation of new ideas, knowledge, and development of creative skills. Thus, the concept of modern education in South Korea identifies seven basic skills of a modern specialist: 1) critical thinking and problem solving; 2) creativity and innovation; 3) cooperation and leadership; 4) intercultural understanding; 5) communication; 6) literacy in the field of information and communication technologies; 7) career and life skills [13]. In the context of the research, especially valuable are the world educational trends covered in the Forbes journal, which correlate with the provisions of the concept of modern education. They are leading role of distance learning technologies; learning personalization and unification aimed at increasing its motivation; gamification of learning (use of game situations in the learning process); introduction of interactive textbooks that provide multidimensionality of the modern educational environment; learning through "interactive immersion" in the virtual world [14].

Thus, smart education is a new philosophy of education, which involves the generation of new ideas and knowledge, the development of critical thinking, creativity, digital literacy, intercultural competence, the ability to cooperate and compete in the modern digital space.

The basic principles of smart education have been formulated in scientific and theoretical thought. Firstly, the educational program should include information that meets the most important current needs to solve educational problems. Modern globalized society is characterized by the rapid growth of information flow. That is why the available educational materials need systematic updating, so that to provide high-quality training of students to solve practical tasks in their future professional activity. Secondly, the organization of students' independent cognitive, research, project activities. Scientists emphasize the crucial importance of this principle in the process of preparing specialists for creative professional activity, independent and research work. Thirdly, the learning process must be continuous and involve learning in a professional environment, using the means of professional activity. Fourthly, the organization of professional interaction with specialists. In the process of learning, students must interact with professionals to gain some positive experience. Fifthly, providing many opportunities for flexible individualized learning and studying educational programs and courses [15].

The abovementioned principles allow us to state that smart education is a new educational paradigm that provides the formation of future philologists' competencies and competencies for flexible, creative interaction in modern society. Consequently, it is an important instrument to form future teachers' readiness for innovation activity.

To clarify the problem of forming future foreign language teachers' readiness for innovative activities in the context of smart education, we have to define the essence of the concept "readiness". The retrospective analysis of researches shows that readiness was initially considered within the framework of regulation and 
self-regulation of human behavior. Subsequently, the concept of readiness was used in the activity theory. Readiness in a broad sense was treated as the initial fundamental condition for the successful realization of any activity, which must be formed and improved both by people themselves and by a system of external factors [16]. In the process of research, it was found that the concept of "readiness" in the modern scientific and pedagogical literature is considered as the unity of personal and professional qualities of the individual that determine productive activity [17].

Educators' readiness for innovative activity is their ability to organize, realize, and regulate innovative pedagogical activity [8]. The analysis of the definitions of the teacher's readiness for innovation allowed us to determine the specifics of its content and provide our vision of the issue. The readiness of a foreign language teacher for innovative activities in the context of smart education is treated as the ability to organize, realize, and regulate innovative professional and pedagogical activities in an intellectual learning environment. This ability is conditioned by the formation of educational, linguistic, and innovative competences.

It has been found that there is a certain uncertainty in modern scientific and pedagogical researches as to the single structure of teacher's readiness for innovative pedagogical activity. Systemic combination of future teachers' educational, linguistic, and innovative competencies in the structures of readiness for innovation activity is common for the presented pedagogical studies. The specific character of a foreign language teacher activity allowed us to determine that teachers' readiness for innovative activity consisting of the following components: motivational, cognitive, creative, reflexive, valeological, technological, and personal.

Regulations on the criteria for teacher's readiness for innovative professional activity, the models of training teachers to innovate provided by I. Havrysh [4], O. Honcharova [8], L. Morska [7], and foreign language teachers' skills determined by $\mathrm{N}$. Meiier and $\mathrm{O}$. Ustymenko [18] gave us the grounds to outline the following criteria and indicators of future foreign language teachers' readiness for innovative activity in the context of smart education:

- motivational criterion (need for innovation; attitude towards the introduction of innovative technologies in foreign language teaching; cognitive interest in introducing innovative technologies in foreign language teaching in the context of multidimensional learning environment);

- content-activity criterion (level of learning outcomes, level of the formation of knowledge about the essence and types of innovative technology in foreign language teaching, the level of formation of skills to implement innovative technology in foreign language teaching in the context of smart education); personal-reflexive criterion (manifestation of future teachers' personal and professional qualities in the process of innovative technology implementation in foreign language teaching (creativity, initiative, independence, activity), ability to reflect, level of readiness for self-development).

Depending on the manifestation of the indicators of these criteria, the formation of levels of future foreign language teachers' readiness for innovative activity in the context of smart education can be determined.

Currently, there are no universal methods for evaluating innovative activity in our country. Most scientists develop their methods based on the theory of the pedagogical process effectiveness or existing methods for evaluating an innovative project. It is explained by the fact that innovative activity in different fields has its specifics and different evaluation criteria (indicators). However, the theory of the pedagogical process effectiveness allows us to assess the effectiveness of resource usage, management systems, and choose the optimal organization of its application in specific conditions.

In the theory of level approach, the level is understood as the ratio between the higher and lower development stages in the structures of some objects or processes. The main criteria for level determination include: belonging of the system to different complexity classes; specificity of laws and patterns on each level; subordination of laws and regularities of lower levels to higher ones; the emergence of systems on each level based on the main structures of the previous one, and each subsequent level refers to the previous one as a system to its elements.

The mechanism of system transition from level to level can be carried out in different ways. Here we can mention complicating element development that leads to structure; creation of a more perfect structure of relations between the elements with their subsequent development to the level of structure development; simultaneous improvement of elements and structure.

V.P Bespalko [19] developed a hierarchical structure of human skills that consists of four successive levels of acquisition, which reflect the development of students' experience in the process of studying a particular subject. The first level - reproductive recognition - presupposes students' reperception of information about the orientation basis of the action. It allows them to distinguish its correct execution from the wrong one by comparing the externally given properties of the object, the source, and final products of the activity. The next level - reproductive algorithmic action - is described as the ability of an individual to independently reproduce information and apply it in different typical situations. The third level is called productive heuristic action and characterizes students' ability to independently reproduce and transform the acquired information to discuss known objects and produce new information about them, as well as to apply the acquired information in various atypical (real) 
situations. The highest fourth level of mastery is a productive creative action. It means that students can use information about objects of activity to obtain objectively new information while finding and discussing the properties of known objects, finding and researching new methods of working with objects, or finding new objects and their properties.

According to I.V. Havrysh, preparation of students in higher pedagogical education institutions for creating, introducing, and distributing educational innovations should be investigated as an open, complex, dynamic, cybernetic system constructed based on the organic unity of the general, special and individual. Thus, the scientist outlines the following levels of students' readiness for innovative activity: pre-professional, elementary, basic, constructive, system [4]. A more simplified system of levels is used by L.V. Kozak. She highlights three levels of teacher training to apply innovations in professional activities: 1) high; 2) average; 3) low [3].

Integrating the results of the above-mentioned authors' researches on the specificity of the level-based approach to determining the levels of students' innovative competence, and taking into account the experience of our work at a higher educational institution, we distinguish three levels of formation of future foreign language teachers' readiness for innovative activity in the context of smart education. They are characterized by the following features:

- high - full, deep, systematic, solid knowledge and skills; creative nature of their acquisition and use;

- medium - gaps in knowledge, reconstructive skills, the ability to situationally use knowledge in practice;

- low - shallow knowledge and skills, unsystematic, chaotic use of them in practice.

\section{Materials and Methods}

In the course of the research, the levels of future foreign language teachers' readiness for innovative activity in the context of smart education were determined. The high level of formation of future foreign language teachers' readiness for innovative activity in the context of smart education is characterized by:

- a steady need for innovation, a positive attitude towards the introduction of innovative technologies in foreign language teaching, sustainable cognitive interest in introducing innovation technologies in foreign language teaching;

- complete, deep, systematic, solid knowledge;

- creative nature of its acquisition and use, complete and flexible knowledge of the essence of innovative technologies in foreign language teaching and their types, advanced skills to diagnose, predict and creatively introduce pedagogical innovations into the structure of teacher's own pedagogical activity; persistent character of future teachers' personal-professional qualities in the process of implementing innovative technologies in foreign language teaching (creativity, initiative, independence, activity);

- constant aspiration for reflecting on innovation activity in the process of foreign language teaching; highly developed analytical and reflexive skills;

- a pronounced ability to comprehend the results of introducing innovative technology in foreign language teaching and correcting their own innovation activities;

- developed, confident skills to successfully organize their further self-education and self-development in the context of innovative technologies in foreign language teaching.

The medium level of formation of future foreign language teachers' readiness for innovative activity in the context of smart education is characterized by:

- a situational need for innovation, an indifferent attitude towards the introduction of innovative technologies in foreign language teaching, occasional cognitive interest in introducing innovative technologies in foreign language teaching;

- gaps in knowledge, the ability to situationally use it in practice, superficial knowledge of the essence of innovative technologies in foreign language teaching and their types, the ability to diagnose, predict and introduce pedagogical innovations into the structure of their own pedagogical activities that are developed at the reproductive level;

- situational character of future teachers' personal-professional qualities in the process of implementing innovative technologies in foreign language teaching (creativity, initiative, independence, activity), insufficient awareness of the importance of reflection on innovation activity, situational reflexive skills, sporadically expressed ability to comprehend the results of the introduction of innovative technologies in foreign language teaching and correction of their own innovation activity;

- the ability to organize their further self-education and self-development in introducing innovative technology in foreign language teaching in the context of smart education, although with some complications, not fully.

The low level of formation of future foreign language teachers' readiness for innovative activity in the context of smart education is characterized by:

- lack of the need for innovation, negative attitude towards the introduction of innovative technologies in foreign language teaching, lack of interest in the introduction of innovative technologies in foreign language teaching; 
- lack of knowledge, its insufficiency, inability to use it in practice, lack of knowledge about the essence of innovative technologies in foreign language teaching and their types, lack of ability to diagnose, predict and introduce pedagogical innovations into the structure of their own pedagogical activity;

- almost non-existent character of revealing future teachers' personal-professional qualities in the process of implementing innovative technologies in foreign language teaching (creativity, initiative, independence, activity), inability to analyze the causes of failures in innovation activity, lack of manifestation of the ability to comprehend the results of innovative technology implementation in foreign language teaching and correction of their own innovation activity;

- the ability to organize their further self-education and self-development while introducing innovative technologies in foreign language teaching in the context of smart education.

The experimental study required applying such theoretical methods as analysis, synthesis, generalization, modelling comparison, induction, deduction. Statistical data analysis was carried out using the non-parametric Pearson's xi-square test.

The reliability, accuracy, and validity of the experimental results were ensured by the implementation of specific measures. In particular, the reliability of experimental data has been provided by the use of standardized techniques and approaches approved by predecessors when determining the level of formation of future foreign language teachers' readiness for innovative activity. The accuracy of the experiment was guaranteed by equal conditions when conducting the experimental study and its actual implementation in the educational process of the higher education pedagogical institution.

\section{Results}

\subsection{Analysis of the Teachers' Survey Results}

To study the problems and prospects of forming future foreign language teachers' readiness for innovative activity in the context of smart education, a pilot study was conducted. It confirmed the relevance of the chosen problem. Certain provisions and conclusions were compared and analyzed during subsequent work, with appropriate corrections made.

The results of targeted pedagogical observations were used as a basis, namely:

- the key aspects of foreign language training for future teachers were discussed;

- interviews, questionnaires, discussions with teachers of higher education pedagogical institutions regarding the significance of innovative technology application in foreign language teaching for the formation of vocational and pedagogical competence of future teachers were conducted;

- lectures and practical classes of teachers at all foreign language courses were attended;

the main motives of the educational, cognitive and professional activity of future teachers for the application of innovative technologies in foreign language teaching were studied;

questionnaires were conducted to identify difficulties, barriers that arise in the course of learning with the use of technological innovations, the formation of abilities to effectively apply acquired professional knowledge, the feasibility of using innovative technologies in foreign language teaching in the context of smart education;

comparative analysis of the examination sessions results was carried out; the level of knowledge in foreign languages, practical skills, and expertise while doing complex control works was diagnosed; testing designed to determine the level of formation of future teachers' foreign language communicative competence; the ability to use innovative methods during different types of pedagogical practices, etc.;

- reports, term papers, diploma projects, and research works were analyzed;

- self-control and reflection were exercised (the following skills were monitored: to analyze, to evaluate own self-education, to correct and develop new tasks, to seek professional development); self-evaluation to identify the degree of students' awareness of the significance of formed professional-pedagogical competence for future professional innovation activities.

Participants of the pilot study were teachers of the Municipal Establishment "Kharkiv Humanitarian-Pedagogical Academy" of Kharkiv Regional Council, Khmelnytskyi Humanitarian-Pedagogical Academy, 55 people in total.

The pilot study made it possible to determine that several difficulties have been encountered in the process of foreign language teaching in pedagogical higher education institutions, namely:

1) distrust towards everything new and reluctance to change the forms and methods of working with students that have been used for many years (42\%);

2) educational interaction of teachers and students is not always based on the development of creativity, activity, and account for individual psychological characteristics of students' age (36\%);

3) an innovative educational environment for the intensive accumulation of foreign language knowledge, skills, and abilities by subjects of education has not always been created; there is no motivation for the acquisition of educational material 
in the process of implementation of innovative technologies in foreign language teaching (52\%);

4) innovative forms of educational activities often cause distrust on the part of teachers, mainly those with work experience (45\%);

5) organization of students' self-work in foreign language classes does not always take into account the specifics of the academic subject and has some shortcomings (37\%);

6) The realization of innovative technologies in foreign language teaching requires a creative approach and creativity both on the part of teachers and students themselves (56\%).

Conclusions drawn on the grounds of the pilot study confirm the data obtained as a result of questionnaires completed by teachers of higher education institutions. The purpose of the questionnaire was to determine the attitude of foreign language teachers to innovative activity in the context of smart education, as well as their level of awareness in the field. At the same time, almost all teachers emphasized that the theory and practice of foreign language education do not ensure the proper level of the formation of students' readiness to innovate in future professional activities in the context of smart education. As a result, they treat the innovative pedagogical activity as separate, although in some way connected processes. Graduates lack fully formed skills to solve creative tasks and problem situations in pedagogical reality using the capabilities of modern smart technologies.

The teachers also noted that the problem of forming future foreign language teachers' readiness for innovative activity in the context of smart education has not only a scientific but also a great practical interest since modern educators should have a good command of a wide range of innovative teaching technologies. Moreover, they should take into account the peculiarities and specifics of the Foreign Language as a subject when making a choice.

\subsection{Analysis of the Students' Survey Results}

In addition to teachers' questioning, a survey with the participation of students (219 students) was conducted. The main purpose of the questionnaire was to determine the students' attitudes to the use of innovative technologies in foreign language teaching. The results of the survey make it possible to draw the following conclusions: students have a positive attitude towards the introduction of innovative technologies in foreign language teaching (79.46\%); future educators are partly aware of the connection between innovative learning technologies and their future professional activities (48\%); there is a need for further improvement of innovative forms of work conducted with students, as indicated by more than half of the respondents (67.5\%); students demonstrate an incomplete readiness to use innovative learning technology in future professional activities (51.3\%); the use of innovative technology in foreign language teaching has often given a positive result (59.2\%); the majority of the respondents (76.4\%) named creativity, criticality, unconventional thinking, and modernity when answering the question "What professional qualities characterize teachers who introduce technological innovations?".

The conducted study made it possible to conclude on the necessity and importance of forming future foreign language teachers' readiness for innovative activity in the context of smart education. It is treated as an ability to organize, realize, and regulate vocational and pedagogical activities and is determined by many factors, among which the most important is the formation of educational, linguistic, and innovative competences. This, in turn, ensures the skilled performance of the innovative professional activity of the foreign language teacher. Structural analysis of the indicators of innovative, language, and training competences became the theoretical grounds for determining the objective criteria for the formation of this phenomenon. Levels of formation of future foreign language teachers' readiness for innovative activity in the context of smart education have been determined based on their interaction.

The pedagogical experiment was conducted to test the hypothesis that the training of future foreign language teachers in a specially designed innovative learning environment will contribute to the formation of their readiness for innovative activities in the context of smart education.

Ukrainian higher education institutions, Municipal Establishment «Kharkiv Humanitarian Pedagogical Academy» of Kharkiv Regional Council, Khmelnytsky Humanitarian Pedagogical Academy, were the experimental base of the research. All stages of the research involved 219 students pursuing their Bachelor's degree in the specialty «014. Secondary education (Language and Literature (English)».

The control and experimental groups in researching the level of future foreign language teachers' readiness for innovative activity in the context of smart education were formed in the following way:

- the control groups (CG) included first-year students of the Faculty of Social and Pedagogical Sciences and Foreign Philology admitted in 2015-2019, as well as students of 2-4 years of 2015-19 academic years. They were trained according to the traditional methodological system using traditional approaches to education;

- the experimental groups (EG) included first-year students admitted in 2015-2019, as well as students of 2-4 years of 2015-19 academic years. They were trained according to the developed methodological system.

To ensure a level playing field during the experiment, 
the following factors were taken into account: first, training in EG and CG was carried out, if possible, by the same teacher. Secondly, CG and EG participating in researching the level of future foreign language teachers' readiness for innovative activity in the context of smart education were formed in statistical equivalence.

To determine the statistical equivalence, the state of future foreign language teachers' readiness for innovative activities in the context of smart education in control and experimental groups was measured (summative check). It involved surveying students aimed at their independent determination of the level of their readiness as future foreign language teachers to innovate in the context of smart education.

Each question is related to a specific criterion of future foreign language teachers' readiness for innovative activities in the context of smart education and checks the level of its formation. Each question is rated from 0 to 4 . According to this scale, all answers are summarized following the relevant criteria. Fig. 1 illustrates the results of the summative check regarding the formation of future foreign language teachers' readiness for innovative activities in the context of smart education.

Fig. 2 illustrates the results of the distribution of students from the groups under research according to the levels of formation of future foreign language teachers' readiness for innovative activities in the context of smart education according to the results of the final check.

The analysis of the results of the formative experiment proves that the implementation of the developed methodology contributes to the formation of future foreign language teachers' readiness for innovative activities in the context of smart education.

The control check showed that experimental group students demonstrated a steady tendency to the formation of their readiness for innovative activities in the context of smart education relative to insignificant changes in the control groups. Studying the results of the formation of future foreign language teachers' readiness for innovative activity in the context of smart education presented in Fig.1, 2 allows for determining an increase in the average value of the selected indicators among the students of the experimental groups, which is more intense than the corresponding changes in the control groups.

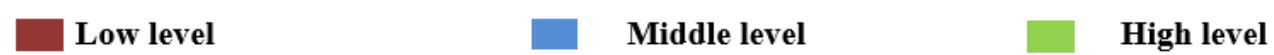

EG1

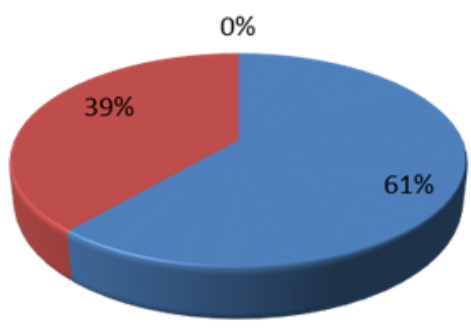

CG1

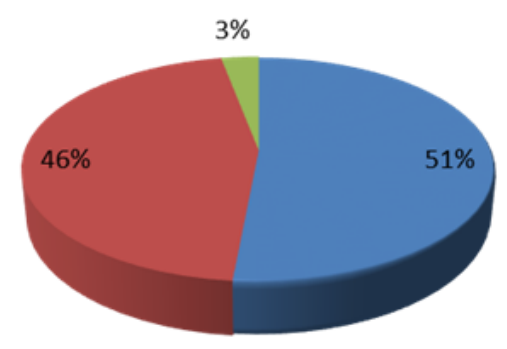

CG2

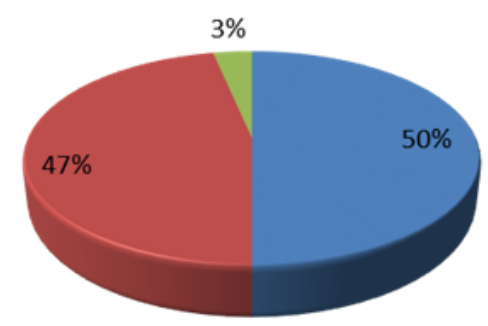

CG2

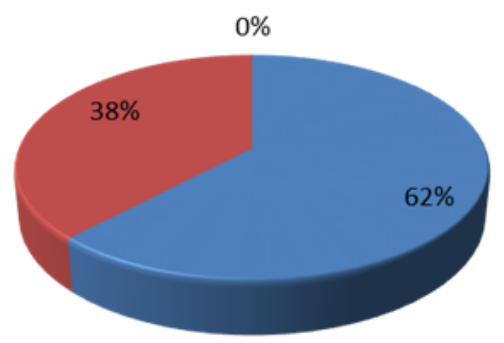

Figure 1. The diagram illustrating the distribution of students from the groups under research according to the levels of formation of future foreign language teachers' readiness for innovative activities in the context of smart education. The summative check. 
EG1
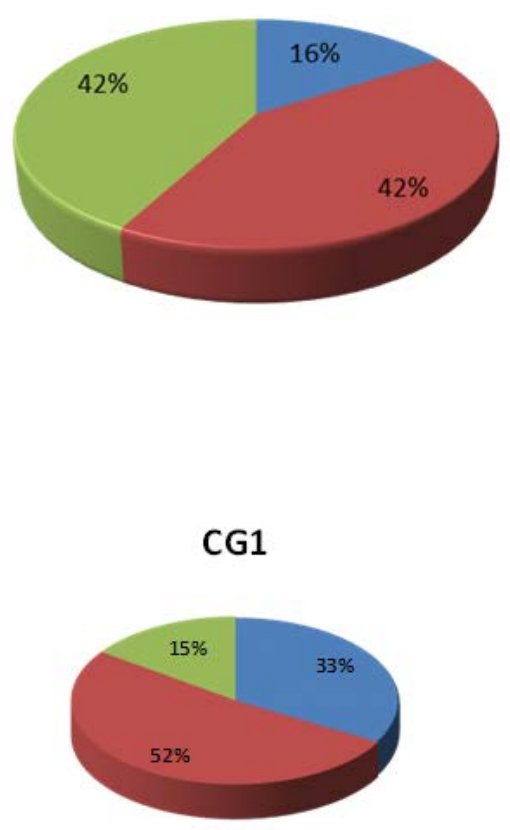

EG2

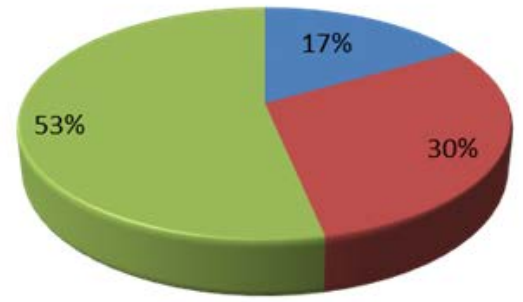

\section{CG2}

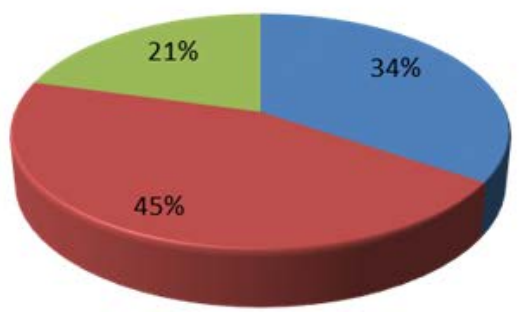

Figure 2. The diagram illustrating the distribution of students from the groups under research according to the levels of formation of future foreign language teachers' readiness for innovative activities in the context of smart education. The final check.

Such quantitative changes in the indicators of the formation of the motivational block of readiness for innovation lead to the conclusion of a qualitative increase in the formation of this block due to the experimental organization of the content block of the methodological system. The recorded changes indicate the effective implementation of the procedural block of the methodological system for the formation of the relevant elements of the cognitive block of the readiness for innovation. Thus, creative tasks that required finding new ways to work with smart technologies, applying knowledge in new situations and self-invention of knowledge in combination with innovative learning technologies that outlined the path of innovation proved to be an effective means of preparing future foreign language teachers for innovative activities in the context of smart education. The intensive growth of indicators of the formation of experimental group students' reflective position testifies the efficiency of the effective block of the developed methodological system for the improvement of the self-regulation block of the readiness for innovative activity. The system of tasks that required assessing personal and others' innovative activities, contributed to the formation of control and evaluation skills, deepening self-esteem, the formation of skills on self-analysis and self-reflection.

The research recorded a $42 \%$ increase in the number of students with a high level of readiness for innovative activities in the context of smart education in EG1 relative to $12.2 \%$ growth in the group CG1. The ratio of these indicators in the groups EG1 and EG2 is 50\% and 20.7\% respectively.

The transition of students from a low level of readiness for innovative activities in the context of smart education is manifested in the following quantitative indicators: $45.3 \%$ in the group EG1 relative to $18.2 \%$ in the group CG1 and $33.3 \%$ in the group EG2 relative to $27.6 \%$ in group CG2. These data indicate the transition of students from low to higher levels (medium, high) of the formation of readiness for innovative activities in the context of smart education. This transition was much greater in the experimental groups, which is a confirmation of the effectiveness of the implemented methodological system of forming future foreign language teachers' readiness for innovative activities in the context of smart education.

The analysis of the research results was performed using the method of nonparametric Pearson's criterion (Xi-square criterion). According to the measurement results, the value of Tn is 6.28 for EG1 and CG1 and 6.92 for EG2 and CG2. We compared these values with the tabular value of Tcr for the significance level $\alpha=0.05$. In this case, $\mathrm{Tcr}=5.991$, which is less than the values we obtained. It allows us to claim that the results of our research are statistically significant. Statistical data confirm the effectiveness of the implemented methodological system of forming future foreign language teachers' readiness for innovative activities in the context of smart education and the validity of the hypothesis. 


\section{Conclusions}

Thus, as a result of our scientific research, the main criteria and indicators of the formation of future foreign language teachers' readiness for innovative activity in the context of smart education have been distinguished. The work is grounded on the consideration of structural features of future foreign language teachers' readiness to innovate through the specification of specialists' orientation towards innovative, linguistic, and educational competences. The formation of these criteria has been classified within three levels: high, medium, and low.

The pedagogical experiment was conducted to test the hypothesis that the training of future foreign language teachers in a specially designed innovative learning environment will contribute to the formation of their readiness for innovative activities in the context of smart education.

The analysis of the results of the pedagogical experiment confirmed the pedagogical expediency of training future foreign language teachers in a specially created innovative educational environment, as it will contribute to the development of their readiness for innovative activities in smart education.

We see prospects for further scientific research in the clarification of measuring scales to specify signs of the formation of future foreign language teachers' readiness for innovative activity in the context of smart education.

\section{REFERENCES}

[1] Teplytskyi O., Semerikov S, Soloviov V., "Professional training of teachers of natural sciences and mathematics using computer modeling: social-constructivist approach: monograph", Theory and methods of teaching fundamental disciplines in higher education, Volume VI, Issue 1 (10), 278 p., 2015.

[2] Hodlevska K., Kobiuk Yu., Preparing a future foreign language teacher for the use of information and communication technologies in professional activities, Kyiv, 2016.

[3] Kozak L., Preparation of the future teacher of preschool pedagogy for innovative professional activity: monograph, Kyiv, 2014.

[4] Havrysh I., "Theoretical and methodological bases of formation of readiness of future teachers for innovative professional activity", the dissertation of the doctor of pedagogical sciences, Kharkiv national pedagogical university named after G.S. Skovoroda, Kharkiv, 2007.

[5] Petrychenko L. "Preparation of the future primary school teacher for innovative activity in extracurricular work, the dissertation of the candidate of pedagogical sciences",
Kirovograd State Pedagogical University named by Volodymyr Vynnychenko. Kirovohrad, 2007.

[6] Mosiiuk O., "Models of preparation of the future teacher of mathematics for innovative activity", Scientific notes of NDPU: Series: psychological and pedagogical sciences, Vol. 2, pp. $35-40,2013$.

[7] Morska L. Information technologies in foreign language teaching, Ukraine, Ternopil, 2008.

[8] Honcharova O., Kaluzhska L., "Reflective component of the readiness of the future foreign language teacher for innovative activities", Problems of modern teacher training, Vol. 7, pp. 25-30, 2013.

[9] Jeong Ji-Seong, Kim Mihye, and Yoo Kwan-Hee, "A Content Oriented Education System based on Cloud Computing", International Journal of Multimedia and Engineering, Vol.8, № 6, pp. 313 - 3286 2013/ DOI: http://dx.doi.org/10.14257/ijmue.2013.8.6.31

[10] Dobrovolska N., Kopniak K., "Smart education as the latest educational paradigm", Smart education: resources and prospects: materials of the international scientific-methodical conference, Kyiv, pp. 40-43, 2016.

[11] Tykhomyrov V., We are on the way to smart society, 2019, URL: http://me-forum.ru/upload/iblock/982/.

[12] Sapohov M., "Smart learning as a technological innovation in the training of masters", Innovative pedagogy, No. 4, Vol. 2, pp. 53-56, 2013.

[13] Korsunska L., "Korean concept of smart education: general education, digital textbooks and smart schools", Education and development of a gifted person, No. 11, pp. 77-80, 2013.

[14] Levyn M., How technology is changing education, 2019, URL:

http://www.forbes.ru/tehno/budushchee/82871-kak-tehnolo gii-izmenyat-obrazovanie-pyat-glavnyh-trendov

[15] Hurevych R., Kademiia M. "Smart education is a new paradigm of modern education", Theory and practice of social systems management, №4, pp. 71 - 78, 2006.

[16] Dolhosh K. "Formation of readiness of a foreign language teacher for innovative activity", New pedagogical thought, No. 2, pp.128-131, 2012.

[17] Honcharenko S., Ukrainian pedagogical encyclopedic dictionary, Rivne, 2011.

[18] Meiier N., Ustymenko O., "Modern methods and technologies for developing pre-service foreign language and culture teachers' methodological competence", Advanced Education, Vol. 10, pp. 12-20, 2018. doi: $10.20535 / 2410-8286.133090$

[19] Bespalko V., "Tools for diagnosing the quality of students' knowledge", School technologies, No. 2, pp. 138-151, 2006.

[20] Kalinina L. V., Bezverkha O. D., Kuzmenko O. A., Antoniuk D. S. The Use of Blended Learning Technologies in the Process of Teaching English at Secondary School. Zhytomyr, 2016. 